\title{
OS REFLEXOS DA INTELIGÊNCIA ARTIFICIAL NO DIREITO E OS NOVOS DESAFIOS DA CARREIRA JURÍDICA
}

\author{
Bruno Augusto Barros Rocha ${ }^{1}$ \\ Ricardo Libel Waldman ${ }^{2}$
}

\section{RESUMO}

Diante de um mundo em constante transformação política, econômica e tecnológica, a sociedade contemporânea está inserida em um processo de mudança em que as novas tecnologias são os principais responsáveis, a chamada Sociedade da Informação. Experimentamos um novo modelo de organização das sociedades baseado em um modo de desenvolvimento social e econômico em que a informação, como meio de criação de conhecimento, desempenhou um papel importante na produção e circulação de riqueza, bem como em contribuir para o bem. bem-estar e qualidade de vida dos cidadãos. Um pré-requisito para o avanço da sociedade da informação é que todos possam acessar novas tecnologias, em particular o avanço da inteligência artificial por meio de algoritmos altamente capazes de influenciar bastante as comunicações pessoais, profissionais e de lazer. Este artigo abordará as aplicações concretas de inteligência artificial e algoritmos de tomada de decisão e os reflexos no sistema jurídico. A metodologia utilizada foi o estudo de caso para identificar por que os fenômenos e a análise bibliográfica. $\mathrm{O}$ objetivo norteador desta pesquisa baseia-se em encontrar respostas sobre as possibilidades de uso, os reflexos e os riscos decorrentes da aplicação desta nova tecnologia no campo do direito, aproveitando as possibilidades que ela pode proporcionar, salvaguardando direitos e garantias, como além de respeitar um parâmetro regulatório.

PALAVRAS-CHAVE: Sociedade da Informação; Inteligência Artificial; Tecnologia; Algoritmos; Sistema do Direito.

\section{THE REFLECTI OF ARTIFICIAL INTELLIGENCE IN RIGHT AND THE NEW CHALLENGES OF THE LEGAL CAREER}

\begin{abstract}
Faced with a world in constant political, economic and technological transformation, contemporary society is inserted in a process of change in which new technologies are the main responsible, the so-called Information Society. We experimented with a new model of societal organization based on a mode of social and economic development in which information, as a means of knowledge creation, played an important role in the production and circulation of wealth, as well as in contributing to the good. well-being and quality of life

\footnotetext{
1 Mestrando em Direito da Sociedade da Informação pelas Faculdades Metropolitanas Unidas - FMU. Especialista em Direito Civil e Processual Civil pela Escola Paulista de Direito - EPD. Especialista em Direito do Trabalho e Processo do Trabalho pela Escola Paulista de Direito - EPD. Bacharel em Direito pelo Centro Universitário das Faculdades Metropolitanas Unidas - FMU. Professor na Universidade Nove de Julho de São Paulo. Advogado. e-mail: brunorocha@adv.oabsp.org.br

${ }^{2}$ Doutor em Direito pela Universidade Federal do Rio Grande do Sul. Coordenador do Mestrado em Direito da Sociedade da Informação do Centro das Faculdades Metropolitanas Unidas e da Escola de Direito da Pontifícia Universidade Católica do Rio Grande do Sul. Membro da Comissão Mundial de Direito Ambiental da União Internacional para a Conservação da Natureza. Advogado. e-mail: ricardolibelwaldman@yahoo.com
} 
of citizens. A prerequisite for the advancement of the information society is that everyone can access new technologies, in particular the advancement of artificial intelligence through algorithms highly capable of greatly influencing personal, professional and leisure communications. This article will address the concrete applications of artificial intelligence and decision-making algorithms and the reflexes in the legal system. The methodology used was the case study to identify why the phenomena and the bibliographical analysis. The guiding objective of this research is based on finding answers about the possibilities of use, the reflexes and the risks arising from the application of this new technology in the field of law, taking advantage of the possibilities it can provide, safeguarding rights and guarantees, as well as respecting a regulatory parameter.

KEYWORDS: Information society; Artificial Intelligence; Technology; Algorithms; Law System.

\section{INTRODUÇÃO}

Este artigo abordará a temática dos reflexos da inteligência artificial no campo do Direito e os novos desafios que a carreira jurídica tem enfrentado face à revolução tecnológica trazida por intermédio da Sociedade da Informação. Através dela, a sociedade tem experimentado um novo modelo de organização, as quais tem sido assentada num modo de desenvolvimento social e econômico pelo qual a informação, vem desempenhando um importante papel na produção e circulação de bens e riquezas, assim como tem contribuído para o desenvolvimento social e cultural dos indivíduos que dela participam.

Importante mencionar, que umas das condições essenciais para a Sociedade da Informação avançar é a possibilidade de todos poderem ter acesso às novas tecnologias, em especial, ao avanço da inteligência artificial e o desenvolvimento constante de Algoritmos altamente capazes de influenciar sobremaneira as relações e interações pessoais e profissionais. Uma das áreas que já vem sendo afetada por esta revolução tecnológica e informacional é o Direito, pois, a recorrente utilização de dados pessoais para alimentar os sistemas de inteligência artificial e a utilização para tomar decisões, podem propiciar uma série de dúvidas e inseguranças.

Neste passo, a disponibilidade de novos recursos computacionais e também em decorrência do aumento de informação, vem resultando o desenvolvimento tecnológico como do paradigma do Big data e proporcionaram o surgimento de sistemas de inteligência artificial que não eram primordialmente baseados em um modelo de regras fixadas, mas sim, que pudessem ser alimentados com grande quantidade de dados, para então poderem fundamentar suas decisões e formar seus padrões de decisão. 
No futuro da sociedade da informação talvez não precisaremos, ou mesmo, nem venhamos a querer que médicos, professores, contadores, arquitetos, clérigos, consultores, advogados e muitos outros profissionais trabalhem como o fizeram até hoje (SUSSKIND, R.; SUSSKIND, D., 2016). Do ponto de vista mais analítico do tema, podemos evidenciar que muito além de discussão, trata-se agora de um desafio a ser enfrentado, pois, a magnitude e a intensidade que a informação e o conhecimento em rede circulam pelo ambiente da sociedade não são descritos com facilidade, tampouco compreendidos.

A reação que resulta dessa dinâmica faz com que a democracia, a legislação política, a prática interpretativa dos tribunais, a doutrina das universidades seja reajustada para essa nova realidade (VESTING, 2016). Contudo, embora o mercado jurídico ainda não tenha experimentado significativas alterações com a chegada da inteligência artificial, é bem provável que em poucas décadas, a forma como os advogados trabalham mudará radicalmente (SUSSKIND, 2017).

Com isso, o objetivo do presente estudo será a análise e investigação de algumas possibilidades de operacionalização de sistemas manipulados pela inteligência artificial, aqui indica-se os algoritmos inteligentes - de modo que eles possam dar apoio aos sistemas da sociedade, dentre eles o Direito, na tarefa de selecionar dados disponíveis no ambiente, tanto pela coleta progressiva ou pela análise da base de dados fornecidos através da sua programação, dando possibilidade de que a escolha a ser realizada seja a mais adequada.

Analisando o tema à luz da academia, temos ainda o objetivo de contribuir, analisar e identificar a busca de soluções condizentes para os problemas existentes nessa sociedade informacional, e para tanto o presente trabalho será organizado de maneira a, em um primeiro momento, apresentar os aspectos conceituais relativos à Inteligência Artificial e os reflexos no Direito e nas carreiras jurídicas. Abordaremos os principais impactos da utilização da IA na carreira jurídica, tais como a substituição da mão de obra humana que faz os mencionados trabalhos de pesquisa jurisprudencial, legislativa e doutrinária. Nesta pesquisa, de modo geral, operam os estagiários dos cursos de Direito, advogados recém-aprovados no exame de Ordem e iniciantes na carreira da advocacia.

E com isso, o estudo se justifica com a possibilidade de identificar uma provável necessidade de atualização dos serviços jurídicos e dos operadores do Direito, em especial, para desenvolver habilidades extras, tais como deter conhecimentos em estatística, economia, redação de qualidade, jurimetria, estruturação de estratégias, entre outros conhecimentos que, 
geralmente, não são trabalhados nos cursos de graduação em Direito. Uma vez que a tecnologia está sempre em constante evolução e transformação, estando os sistemas mais inteligentes e processando mais informações com grande capacidade sobre-humana. Com isso, acreditamos que será necessário aos profissionais que desenvolvam novas habilidades, a fim de executarem tarefas mais estratégicas nos negócios de seus clientes, uma vez que as tarefas repetitivas de menor complexidade serão executadas com grande facilidade pela inteligência artificial.

Para nortear a discussão em torno dessas questões se vai à fonte criadora da tecnologia, incursionando no modo como ela se estrutura e se organiza. Parte-se, então, da visão de Alan Turing, considerado o pioneiro na criação da inteligência artificial nos anos 1950, na compreensão e na utilização dos algoritmos no ensinamento das máquinas. Leva-se em conta também a divisão consagrada pelo filósofo John Searle entre inteligência forte e fraca, para limitar o campo de utilização da nova tecnologia. Segue-se ampliando o olhar para os fundamentos filosóficos aristotélicos em torno do método silogístico que embasa o ensinamento da máquina para alcançar o conhecimento, procurando estabelecer os limites e perigos que se tem pela frente.

Por fim, se ingressa na discussão a respeito da inteligência artificial e seus reflexos no sistema de Direito, em especial na carreira jurídica que deverá de preparar para esse novo mundo, bem como o profissional desta seara que deverá se anteceder, inclusive, se atualizando e estando atento também as atualizações das legislações, tornando-se apto para ações judiciais provenientes destas arestas que inteligência artificial ainda não alcançou com sua expertise e excelência.

\section{EVOLUÇÃO DA INTELIGÊNCIA ARTIFICIAL E DOS ALGORÍTIMOS}

A inteligência artificial, manipulada por intermédio dos algoritmos, tem como função de destaque produzir previsões (ZARSKY, 2013, p. 1505). A aplicação da inteligência artificial no cotidiano pode ser utilizada para previsões de fatos gerais (economia, natureza ou política), bem como para prever um comportamento individual.

Nas decisões automatizadas, referentes a um indivíduo determinado, e que se baseiam num método estatístico para análise de um grande volume de dados e informações, pode ter impacto demasiado sobre os Direitos individuais. Afinal, na sociedade cotidiana, 
dados pessoais acabam constituindo uma única forma de representação das pessoas perante diversas organizações estatais e privadas, sendo determinantes para "abrir ou fechar as portas de oportunidades e acessos" (LYON, 2003, p. 27).

Não se pode olvidar da relevância econômica e social de decisões tomadas com base nos algoritmos, e seria deveras difícil pensar no funcionamento da sociedade contemporânea sem a utilização deles. Destaca-se que uma das funções precípuas do processamento dos dados por meio de algoritmos atualmente é o fornecimento das bases para decisões econômicas, de modo a contribuir para a mitigação de riscos nos negócios (BUCHNER, 2006, p. 138; MENDES, 2014, p. 94).

Sabe-se que e Estado se utiliza há tempos de decisões automatizadas para o cumprimento das funções de seus diversos órgãos públicos. Como bem sinalizado por Citron (2008, p.1259) em sua descrição do "Governo 2.0", o aumento da utilização de decisões automatizadas por agências de governos internacionais nos últimos anos tem diversos fundamentos, tais como a diminuição os custos e melhoria da performance de sistemas automatizados, bem como surgimento da rede de Internet e a redução de custos com recursos humanos. Nesse espectro cotidiano, inúmeras decisões tomadas pelo Estado são efetuadas por meios automatizados, seja no auxílio ao combate à evasão fiscal (ZARSKY, 2013, p. 1511) e no combate ao terrorismo (PASQUALE, 2011, p. 236), seja nas empresas que receberão licenças de funcionamento, das crianças que receberão assistência médica e dos passageiros que poderão embarcar em determinados voos (CITRON, 2008, p.1259).

Vale frisar, especialmente sobre a necessidade de se atentar à promessa de que as decisões baseadas em algoritmos costumam suscitar uma obtenção de maior objetividade nas decisões e a possibilidade de fundamentação em critérios estatísticos, eliminando assim, um possível risco dos vieses distintos típicos das decisões tomadas pelos humanos. De outro lado, grande parte da literatura tem demonstrado o risco iminente de discriminação aos processos de tomada de decisão baseados em algoritmos, a qual ocorre em diversas vezes, de forma involuntária e sem o conhecimento dos tomadores de decisão (BAROCAS, 2015, p. 3).

Observe-que qualquer algoritmo só é bom como outros dados que lhe servem como base (BAROCAS, 2015, p. 1). Quer dizer que, a qualidade da decisão automatizada (“output"), baseada em um algoritmo, tem uma relação direta com a qualidade dos dados que ele processa ("input"). Assim, se o algoritmo se baseia em dados históricos repletos de 
preconceitos, de forma automatizada, ele reproduzirá, os mesmos padrões preconceituosos utilizados e constantes na base de seu processamento.

Ocorre que a denominado "big data", acaba apresentando ainda mais desafios no tocante aos riscos de discriminação algorítmica por uma série de motivos. Os dados estão revolucionando a sociedade, destacando o que muitos chamam de a Quarta Revolução Industrial (SCHAWAB, 2016). Enquanto a Primeira Revolução Industrial foi embasada em água e vapor para mecanizar a produção, e a Segunda utilizou a energia elétrica para criar produção em massa, sabe-se que a Terceira Revolução Industrial alavancou a eletrônica e a tecnologia da informação para automatizar a produção. Atualmente, devido ao número de tecnologias que estão se integrando no nosso dia a dia de modo progressivo, defende-se que estamos diante da Quarta Revolução Industrial, a qual amplamente alimentada por dados, vem eliminando as fronteiras tecnológicas.

Com o fito de ilustrar a acima exposto, destaca-se dentre as áreas de aplicação da inteligência artificial, o Machine Learning que certamente é a mais utilizada, eis que permite o desenvolvimento de sistemas com habilidades para apreender e aprimorar conhecimentos através de experiências sem que tenham sido programados para tal finalidade. significa dizer que os sistemas são capacitados para detectar e entender e aprender com os dados que ele analisa. Ademais, o sistema se adapta e aprende na medida em que as informações vão sendo por ele acumuladas (BENGIO, 2014).

Com relação a tecnologia que move a "Natural Language Processing" possibilita que os computadores possam analisar, entender e até mesmo concluir com base na fala. e neste sentido, as traduções, análises de sentimentos e outras, são o centro de suas aplicações. Já o Deep Learning se encontra em nível mais sofisticado. A capacidade engloba a percepção e a assimilação de múltiplos e complexos comportamentos e padrões. Vale destacar que, tudo isso de forma bastante intuitiva, o que faz o sistema descobrir técnicas para resolução dos problemas que talvez o humano mesmo com todo seu esforço e talento, tenha levado bastante tempo para aperfeiçoar (BENGIO, 2014).

Assim, a partir dessa percepção, o sistema está apto a apresentar resultados para inúmeras tarefas, tais como aquelas relacionadas ao Direito, assemelhando-se com extrema precisão cirúrgica aquelas tarefas desempenhadas pelos seres humanos. No entanto, embora a utilização da inteligência artificial na esfera do Direito ainda esteja incipiente, se comparado com outras áreas do conhecimento, tais como indústria e medicina, já se faz perceptível 
visualizar uma mudança de rumo e transformação, uma vez que os grandes escritórios de advocacia começaram a compreender as vantagens da inteligência artificial, inclusive a implantando para acompanhar o ritmo desta evolução (BARBOSA, 2016. p. 240-241).

Assim, fica fácil perceber que "a relação mutante constitutiva entre o Direito e espaço é condicionada pela circulação de informação" (BARBOSA, 2016. p. 242). Isso demonstra uma clara existência de um grande volume de informação que está disponível no ambiente do sistema do Direito. Destaca-se que é bastante grande e ultrapassa a capacidade razoável estrutural do próprio sistema em selecioná-las e compreendê-las. De fato, há mais informações no ambiente do sistema que a capacidade do próprio sistema em utilizá-las.

\section{A INTELIGÊNCIA ARTIFICIAL E OS REFLEXOS NO SISTEMA DO DIREITO}

A inteligência artificial no Direito pode se traduzir na aplicação das tecnologias na seara jurídica, ou seja, fazendo uma interpretação simplória, quando uma máquina ou programa e até mesmo um sistema ou aplicativo simula o raciocínio de um advogado ou outro profissional do Direito. Os algoritmos são desenvolvidos para tomar decisões, podendo vir a substituir por completo a mão de obra humana em determinadas tarefas. Por outro lado, destaca-se que, um software jurídico, não é, necessariamente, uma solução de inteligência artificial no Direito, por exemplo.

Os programas desse tipo se espalharam bastante nos escritórios de advocacia há algum tempo, e tem tornado o trabalho dos advogados muito mais ágil, eficiente, organizado e simples. No entanto, tais sistemas, só poderá ser considerados soluções de inteligência artificial se deixarem de ser uma simples ferramenta de suporte administrativo-jurídico, para de fato auxiliar nas decisões relacionadas às atividades fins do escritório, tal como a consultoria e até mesmo a representação jurídica (Zavaglia Coelho, 2018).

Assim, defende-se que a inteligência artificial no Direito é resultado da evolução gradual das tecnologias da informática, já que inicialmente, as planilhas digitais simplificaram muito o armazenamento e consulta a dados relevantes para processos, decisões e estratégias de defesa ou acusação. Atualmente, soluções de big data, por exemplo, permitem processar dados de maneira muito rápida e assertiva, de modo que o resultado é a redução de tempo com pesquisas e consultas a bancos de dados(Zavaglia Coelho, 2018). 
Com a inteligência artificial no Direito, a sociedade da informação evolui, pois os algoritmos aproveitam todos esses dados para tomar ou sugerir decisões de modo assertivo, bem como conseguem apontar riscos e expor correlações ou incongruências. Portanto, essa tecnologia, faz muito mais do que apenas substituir o trabalho dos advogados humanos. Ocorre que, essa nova realidade passa a ser visualizada igualmente na seara jurídica e muito embora possa levantar dúvidas, suspeitas e incertezas, por outro angulo, igualmente produz expectativas, já que a inteligência artificial possibilita a realização de inferências, conexões e correlações na seleção de dados do ambiente do sistema parcial do Direito que dificilmente seriam factíveis aos operadores do Direito.

Fato é que ainda estamos no começo dessa Quarta Revolução Industrial, a qual possui uma característica marcante a qualquer tipo de revolução enquanto ela está acontecendo, que é o fato da dificuldade de reconhecê-la como tal revolução. Certamente que daqui alguns anos, será muito mais fácil explicar qual foi o impacto da inteligência artificial em nossa sociedade jurídica, pois as soluções já terão se consolidado, amadurecido e se popularizado.

Na verdade, essa revolução silenciosa já está em curso, e a maior parte do universo jurídico ainda parou para observar a velocidade dos acontecimentos e os reflexos da inteligência artificial no ambiente legal (SUSSKIND, 2017). Essa nova realidade irá alterar radicalmente o que sabemos e o que conhecemos da seara do Direito, como o fez com inúmeras outras áreas. À guisa de exemplo, imaginemos no sistema da medicina, no qual o especialista realizava o diagnóstico de um paciente com uma autoridade quase absoluta, aqui vale destacar, que pouco se importando com dados ou conceitos estatísticos. No entanto, essa lógica tem sido revista a ponto de o especialista listar evidências, ao passo que o algoritmo inteligente vem a indicar qual a doença e qual o tratamento a ser ministrado para determinado paciente.

Na história do Direito à luz da sociedade da informação, o primeiro robô que desempenhava funções de um advogado e desenvolvido com essa tecnologia foi o Ross Intelligence (IBM, 2017b) e sua finalidade foi atender o escritório americano Baker \& Hostetler. O robô possui inúmeras habilidades, dentre elas, a capacidade de ler e até mesmo compreender a linguagem natural para desenvolver hipóteses se assim questionado. bem como realizar a pesquisa jurídica (inputs) e gerar até mesmo as respostas ou conclusões fundamentadas (outputs) sem a interferência humana. 
E mais, ele é capacitado para aprender através de suas experiências, ou seja, permitindo que ele ganhe velocidade e conhecimentos oriundos de suas próprias interações. E se não bastasse, o "Ross" tem a capacidade de armazenar toda a legislação necessária, mantendo-a atualizada constantemente, bem como toda a jurisprudência, ou mesmo precedentes e demais fontes do Direito. Há também um programa, cujo projeto denominado "Supreme Court Forecasting Project" permite que os algoritmos realizem inferências e previsões com grau elevado de probabilidade assertiva do resultado dos julgamentos de casos futuros que possam ser realizados nos EUA. Para isso, ele utiliza o programa da seleção, manipulação e aprendizado de dados públicos sobre as decisões judiciais já proferidas, como uma espécie de banco de precedentes. ${ }^{3}$

De modo bastante embrionário, no Brasil essa nova tecnologia começa a despontar na área jurídica. Tanto que muito se fala sobre o "Assistente Digital do Magistrado", bem como o "Assistente Digital do Promotor" e até mesmo o "Assistente Digital das Procuradorias", são alguns exemplos domésticos de programas que se utilizam da inteligência artificial. Tais programas constroem peças processuais, dentre as quais ficam aptas e prontas para serem enviadas pelo internet ao Judiciário, bem como fazem contestações, e até mesmo realizam buscas na jurisprudência para auxiliar a tomada de decisão sem que o humano tenha participação, tampouco tenha contribuído para esse processo.

$\mathrm{Na}$ realidade, os algoritmos na sua quase totalidade dotados de inteligência artificial são plenamente aptos a realizar operações até mais complexes e para tanto, requerem o acesso e a utilização de dados, informações, conhecimento, raciocínio, estatísticas, evidências, dentre outras habilidades. Logo, a área jurídica mostra-se apropriada a operação de tais sistemas, uma vez que são regidas por princípios, leis, normas e regulamentos, que podem ser objeto de aprendizado pelos algoritmos inteligentes, como já tem sido feito. ${ }^{4}$

De fato, as máquinas sempre representaram, e ainda representam grande expectativa de benesses e também de riscos, e aqui optamos em dedicar a pesquisar as perspectivas positivas da utilização da tecnologia à favor do área jurídica, seja pela sua utilização como suporte a uma decisão judicial, ou mesmo pela possibilidade de disseminar a expertise e conhecimento como jamais foi visto anteriormente. Por fim, defende-se que essas

\footnotetext{
${ }^{3}$ IBM. Ross intelligence. New York, 2017b. Disponível em: <http://www.rossintelligence. com/>. Acesso em: 10.abr.2020.

${ }^{4}$ https://www.conjur.com.br/2017-abr-28/mp-comeca-usar-inteligencia-artificial-elaborar-acusacoes. Acesso em: 10.abr.2020.
} 
perspectivas demonstram ser um caminho sem volta, o qual só se saberá do resultado futuramente.

\section{OS REFLEXOS DA INTELIGÊNCIA ARTIFICIAL NA CARREIRA JURÍDICA}

Analisando o caso dos advogados, é de suma importância destacar que a rotina será transformada segundo o destacado anteriormente. A inteligência artificial ajuda os causídicos a otimizarem uma parte considerável de seu trabalho, trazendo a ideia de que tarefas de menor complexidade e até mesmo repetitivas, sejam resolvidas com facilidade. Ademais, defende-se que a inteligência artificial no Direito também deve impactar o serviço dos órgãos do Poder Judiciário.

Discute-se que a esperança nessa tecnologia é para que traga mais celeridade nos processos judiciais e ajude a mitigar falhas para construir uma sociedade mais justa. A guisa de exemplo, vale citar o caso da Estônia, que tem o plano de desenvolver um "juiz robô" para se encarregar de causas menores e mais simples, liberando os juízes humanos para analisar matérias mais completas (SILVA, 2019).

Neste passo, para a população em geral, o primeiro benefício é a da expectativa de se ter uma Justiça mais eficiente, ágil e com maior grau de acerto, ou seja, mais justa. E, também se espera que fique muito mais simples obter o serviço de prestação jurisdicional. Fala-se de inovações disruptivas, as quais trazem ao mercado práticas e lógicas diferentes, e até mesmo modelos de negócio novos. Vale lembrar que, quando surgiram os softwares jurídicos e outras ferramentas mais básicas, como os programas de edição de documentos e planilhas, muitos se comentou acerca do mercado de profissionais da seara jurídica, sabe-se que o Direito não se trata apenas de análises frias e objetivas da lei.

Para o Direito, há que ser observado as questões éticas e interpretar a subjetividade de cada caso à luz do fato e da norma, logo, um raciocínio que as máquinas não são capazes de conduzir. Para Miguel Reale, ao analisar-se fenomenologicamente a experiência jurídica o Direito é estruturalmente tridimensional, sendo percebido como elemento normativo, que disciplina os comportamentos individuais e coletivos, que pressupõe uma situação de fato que se refere a valores determinados. Ocorre que, não existe uma dinâmica estática entre tais elementos. Como assevera o autor, acontece na verdade "apenas um predomínio ou 
prevalência de sentido, e não uma tripartição rígida e hermética de campos de pesquisa" (REALE, 1999, p. 510).

Desse modo, ao analisar tal conjuntura entra-se no estudo das espécies das teorias tridimensionais, quais sejam o tridimensionalismo específico e tridimensionalismo genérico. Segundo Reale, é possível entender o tridimensionalismo específico como a real admissibilidade do entendimento da pesquisa acerca do Direito através da reflexão conjunta dos três elementos. Senão vejamos:

\footnotetext{
"o que denominamos tridimensionalismo específico assinala um momento ulterior no desenvolvimento dos estudos, pelo superamento das análises em separado do fato, do valor e da norma, como se se tratasse de gomos ou fatias de uma realidade decomponível; pelo reconhecimento, em suma, de que é logicamente inadmissível qualquer pesquisa sobre o Direito que não implique a consideração concomitante daqueles três fatores”. (REALE, Miguel, 1999, p. 513, grifo nosso)
}

Dentre os fundamentos da teoria da tridimensionalidade do direito realizada por Miguel Reale há a marcante característica do culturalismo, que é facilmente percebida pelo reconhecimento do autor, ao analisar a tríade fatorial da teoria, a necessidade de análise da realidade social e cultural onde ela se apresenta. Diante disso, Miguel Reale consegue extrair da relação entre os três fatores da teoria do Direito o fato de que não se pode olvidar a realidade jurídica a qual se apresenta, de modo que o caráter valorativo é conexo ao cultural. Ocorre que, vem acontecendo sempre a evolução da tecnologia, que desencadeará numa transformação dos profissionais. Frise-se que a tecnologia substitui apenas uma parte do trabalho, e traz vários benefícios, tais como, mais tempo para se dedicar ao planejamento e execução da estratégia aumentando as chances de se obter o resultado esperado.

Neste sentido, por se tratar de uma ciência não estática, o Direito permite que a pessoa humana busque mecanismo capazes de lhe trazer melhoramentos decorrentes da informatização do conhecimento. Vale acrescentar, que a adoção de máquinas e programas inteligentes no meio jurídico coopera na redução de processos e agilidade das decisões processuais. "Nos idos dos anos 70, diversos pesquisadores europeus já se dedicavam ao estudo do impacto das tecnologias no Direito". E, ainda na opinião de FERRAGUT:

"A doutrina moderna reconhece que a vontade que dá origem ao ato administrativo deve ser dotada de critérios objetivos ante a incidência do princípio da impessoalidade. Sendo assim, é imperioso que se reconheça a existência e a validade do ato administrativo praticado por softwares inteligentes da administração pública. Os atos seriam praticados de forma efetivamente impessoal, rápida e uniforme. A 
sociedade só teria a ganhar com isso". (FERRAGUT, SILVA, Maria Rita e Renata Elaine, 2010, p.25).

É cediço que o tratamento não diferenciado nas demandas judiciais, indicam a ineficiência do sistema judiciário. Destaca-se ainda que seja necessária essa diferenciação, com o fito de mudança do cenário do judiciário. Assim, a ruptura é eficaz, no intuito de desenvolver mecanismos mais eficientes com instrumentos tecnológicos, possibilitando automatizar os atos jurídicos. Alguns fatores analisados por (RAVAGNANI, 2017) para automatizar o judiciário são:

\footnotetext{
“As juntadas de petições podem ser automáticas, assim como a expedição de mandados, guias de levantamento, certidões de objeto e pé. Também pode ser automática a remessa dos autos à conclusão após a juntada de uma petição, a intimação de um perito via e-mail, a indicação de uma decisão judicial para publicação no Diário Oficial, a certificação de decurso de prazo, a conferência do pagamento de custas judiciais, o agendamento de audiências etc. Em suma, todos os procedimentos administrativos processuais podem ser substituídos por um software."
}

Defende-se assim, que atualmente e mesmo futuramente haverá disputa homem versus máquinas, no entanto, considera-se ainda que, a diferença entre o homem da máquina será a inteligência emocional, assim ligado ao sentimento. Com isso, a profissão jurídica poderá ter inteligência artificial como aliada ou mesmo até uma ameaça, para tanto, dependerá de ser analisado quando todos estiverem inseridos nesse contexto de acordo com Susskind (apud HOGEMANN,2018).

Vale lembrar que, a tecnologia não destrói profissões inteiras de uma vez, e claro que, os advogados, os contadores ou médicos não vão chegar no trabalho e encontrar um robô sentado no lugar deles. Na verdade, o que a inteligência artificial faz é mudar as tarefas e atividades que as pessoas realizam, o que em médio prazo poderá gerar uma espécie de redistribuição, mas não um desemprego em massa. Essa é uma história na qual as tarefas e atividades que precisem de conhecimentos profundos e específicos serão bem diferentes e provavelmente serão feitas por pessoas diferentes e mais qualificadas (SUSSKIND, 2018).

Novamente falando sobre primeiro robô advogado, ele tem como premissa acelerar o andamento dos processos e reduzir erros. "O sistema ELI, Inteligência Legal Melhorada, idêntica tem a função de organizar processos e jurisprudência de forma autônoma". O resultado de dados coletados fornece a garantia em uma decisão do profissional, dessa forma as informações são confiáveis. Acredita-se que a inteligência artificial trará uma maior 
funcionalidade na gestão de processos e tornará a profissão de advocacia mais assertiva e criativa, uma vez que substituirá o trabalho de menor valor agregado. Neste sentido, infelizmente se considera que as profissões com salários ínfimos face à menor qualificação, serão substituídas pelos algoritmos e robôs. ${ }^{5}$ Defende-se também, que advogado não será desvalorizado por isso, abrindo uma larga vantagem para o trabalho intelectual, já que serão requisitados para análise de resultados, resolução de casos e aconselhamento de clientes, ou seja, farão parte da nova cultura, a cultura da prevenção e do compartilhamento do conhecimento.

Frise-se que o novo diferencial do advogado perante a esta tecnologia, será o fato de deixar de fazer trabalhos repetitivos e de menor complexidade, valorizando assim o seu conhecimento, expertise e raciocínio lógico, os quais ficarão disponível para uma maior efetividade nos assuntos complexos, onde o intelecto é peça primordial para estudar novas teses e definir abordagens e estratégias eficientes para a execução de um bom processo. Os advogados que não quiserem dividir conhecimento serão postos de lado. (SUSSKIND, 2018)

Existem companhias que oferecem trabalhos para que o cliente possa desenvolver funções como um profissional jurídico da categoria do faça você mesmo. Em 2011, o Google Ventures aplicou 18,5 milhões de dólares na Rocket Lawyer, software que auxilia as pessoas a eliminarem ambiguidades referentes a legislação e a oficializar determinados contratos de forma segura (SOARES,2018, p.1).

Defende-se que essas novas ferramentas tecnológicas disponíveis para os advogados utilizarem nos serviços jurídicos irão facilitar positivamente conforme já mencionado nesse artigo, no entanto, vale destacar que a automação da advocacia está alterando a relação profissional e cliente com a utilização de aplicações de software que simulam ações humanas de maneira padrão. Neste sentido, a $1^{\text {a }}$ turma de ética Profissional do Tribunal de Ética e Disciplina da seccional paulista da Ordem dos Advogados do Brasil avaliou que as inovações tecnológicas são importantes para auxiliar o advogado no exercício de suas funções (VIDIGAL; LIMA, p.1,2018).

Os operadores do Direito deverão modificar a forma de desempenhar o trabalho nesse novo cenário, uma vez que os algoritmos e a inteligência artificial trarão um novo conceito, inclusive, modificando e interagindo o ambiente de trabalho, sendo inevitável essa

\footnotetext{
${ }^{5}$ https://pradomachadoadv.jusbrasil.com.br/noticias/485256692/robo-advogado-usa-inteligencia-artificial-paraacelerar-processos-judiciais. Acesso em: 10.abr.2020
} 
interação entre o homem e a máquina. Com isso, além de desenvolver habilidades para gestão, os profissionais deverão ter uma aprendizagem profunda, sendo necessário ter conhecimento em diferentes áreas do campo do saber. Também merece destaque vez mais que, se torna é improvável substituir os humanos pelos robôs, pois, essa tecnologia é cara e não será acessível para todos, no entanto, repita-se que para o sucesso dos negócios, o acompanhamento dessa tecnologia se torna indispensável (SUTTO, p.1.2018).

Sabe-se que a profissão jurídica vem mudando com a informatização de atos judiciais, sendo fundamental que o profissional da área jurídica esteja inseridos nesse novo cenário que exige conhecimento de novas áreas e tecnologias, que até então não eram necessários para exercer a profissão de forma eficaz, e de acordo com o advogado Caio César Carvalho (apud FIGUEIREDO, 2015, p.1) explica que:

\footnotetext{
Além de todo conhecimento jurídico, inclusive com relação à jurisprudência específica, espera-se que o novo profissional tenha noções básicas de tecnologia entendendo o que é IP (Internet Protocol), provedor de conexão, provedor de aplicação, procedimentos de quebra de sigilo, arquitetura de rede, entre outros -, bem como que tenha inglês fluente, considerando que são frequentes os contatos, por escrito e por voz, com provedores localizados fora do Brasil.
}

A automação e a inteligência artificial no Direito não podem ser vistas como tecnologias negativas ou contrárias ao desenvolvimento social, tampouco que trarão desemprego e prejuízos à economia, pois, são soluções que qualificarão as atividades dos profissionais ligados à área jurídica, tornando os serviços jurídicos mais especializados e acessíveis à coletividade. Para tanto, é essencial buscar não apenas um entendimento sobre o funcionamento das tecnologias, mas também o desenvolvimento intelectual em geral, tal como, conhecer a lógica dos algoritmos e aprender a manusear as soluções de inteligência artificial no Direito é muito importante. O profissional também precisará se preparar para aproveitar o tempo que a automação dos programas vai trazer, inclusive, poderá ser a oportunidade perfeita para aperfeiçoamento intelectual ou para aprimorar a prospecção e atendimento aos clientes.

\section{CONCLUSÃO}

O tema tem potencial para traçar um panorama de alguns aspectos atuais de projeção de sistemas de inteligência artificial que se vão inserindo cada vez mais no cotidiano dessa 
sociedade informacional, e que, carece de atenção pelos potenciais efeitos no ordenamento jurídico pátrio, seja pela necessidade da criação de novos institutos ou mesmo de adaptação dos existentes, mas também pela própria abertura de debate sobre alguns de seus conceitos fundamentais. Dá-se a impressão, que há outras particularidades que devem igualmente abordadas, haja vista a possibilidade de gerar efeitos horizontais para o ordenamento jurídico, como por exemplo, o potencial das tecnologias de algoritmos e da inteligência artificial para estender capacidades humanas.

O avanço tecnológico e da utilização de inteligência artificial é irremediável, e por já estar em curso, deveras ser debatido as possibilidades e implicações destas tecnologias no mundo jurídico, pois, o universo jurídico do futuro, talvez ou pouco se assemelhe ao que conhecemos hoje. Neste passo, as instituições jurídicas e os profissionais que atuam nessa área, sejam eles advogados, juízes, promotores e até os servidores, podem entrar numa encruzilhada, embora poucos tenha se falado a respeito ou mesmo ainda muitos não tenham se apercebido disso. Se faz imperioso imaginar como será a reação dos operadores do sistema legal quando os algoritmos sofisticados e inteligentes forem capazes de localizar mais precedentes, ou então, de analisar toda a legislação e doutrina existente em poucos minutos, provavelmente de forma mais eficaz e assertiva do que o humana.

E aqui, haverá nítido contraste com a capacidade dos humanos de serem capazes de realizar o mesmo trabalho durante uma vida inteira. Talvez esses usuários trabalhadores tenham que voltar para os bancos da academia para apreenderem novos ofícios ou mesmo uma nova profissão. No entanto, um olhar diversos pode demonstrar que ao retornarem à academia, tais profissionais poderão descobrir que a inteligência artificial já alterou aquele sistema de educação há tempos e a tarefa de manter-se atualizado com as últimas decisões no campo jurídico e a gama de legislações que entram em vigor diariamente faz parecer impossível que um ser humano consiga compreender o universo de dados que movem esse campo do saber.

Com isso, tarefas que antes eram realizadas manualmente pelos humanos, agora, passam a ser realizadas por sistemas inteligentes de algoritmos e inteligência artificial. Certo é que haverá tarefas complexas no campo legal que talvez a inteligência artificial não consiga desempenhar e certamente algumas tarefas estão fora do alcance das máquinas na atualidade. No entanto, não quer dizer que o restante do trabalho daquela profissão não possa ser desempenhado por aquele agente inteligente e de forma mais rápida, eficiente e assertiva. 
Provavelmente tenhamos dificuldades para encontrar todas as respostas dessas ponderações, no entanto, pensamos nas implicações e perspectivas positivas a serem enfrentadas pela profusão e utilização da inteligência artificial na seara jurídica e da sociedade, ressaltando que este será um caminho sem volta. Logo, mais eficaz do que competir com toda a tecnologia, é entender seu funcionamento e aproveitar das possibilidades que ela possa proporcionar para a resolução dos problemas da sociedade. É preciso reconhecer o impacto da chegada dessa tecnologia no universo jurídico, bem como, as oportunidades que dela advirão.

Com isso, o Direito precisa preparar-se para esse novo mundo, bem como o profissional da seara jurídica deverá se anteceder, inclusive, se preparando e se atualizando, estando atento também as atualizações das legislações, estando apto para ações judiciais provenientes destas arestas que inteligência artificial ainda não alcançou com sua expertise e excelência. Conclui-se também que a criação da inteligência artificial foi o maior invento da humanidade, mas também poderá ser o último se não soubermos evitar os seus males e conduzi-la ao bem da sociedade informacional.

\section{REFERÊNCIAS}

ASIMOV, Isaac. Eu, robô. São Paulo: Aleph, 2014.

BARBOSA. Samuel (Coord.). Teorias contemporâneas do Direito: o Direito e as incertezas normativas. 1. ed. Curitiba: Juruá, 2016. p. 140-142.

BENGIO, Youshua. Learning Deep Architectures for AI. Foundations and Trends in Machine Learning, e. Now Publishers, 2014.

BIG DATA: Credit where credit's due. Financial Times, 2015. Disponível em: <https://www.ft.com/ content/7933792e-a2e6-11e4-9c06-00144feab7de>. Acesso em: 10.abr. 2020.

BERTALANFFY, Ludwig Von. Teoria geral dos sistemas: fundamentos, desenvolvimento e aplicações. Petrópolis: Vozes 2014.

BRITZ, G. Freie enfaltung durch selbstdarstellung. Tübingen: Mohr Siebeck, 2007.

BUCHNER, Benedikt. Informationelle selbstbestimmung im privatrecht. Tübingen: Mohr Siebeck, 2006.

CALO, Ryan. Robotics and the lessons of cyberlaw. California Law Review, Berkeley, v. 103, n. 3, p. 513-563, jun. 2015. 
CAMPOS, Ricardo; BARBOSA. Samuel (Coord.). Teorias contemporâneas do Direito: o Direito e as incertezas normativas. 1. ed. Curitiba: Juruá, 2016. p. 96-99.

CASTELLIS, Manuel. The rise of the network society. Blackwell: Oxford, 1996.

CASTRO JÚNIOR, Marco Aurélio. A personalidade jurídica do robô e a sua efetividade no Direito. Salvador, Universidade Federal da Bahia, 2009. Disponível em: <https://repositorio.ufba.br/ri/handle/ ri/10719>. Acesso em: 10.abr. 2020.

COPPIN, Bem. Inteligência artificial. Tradução e revisão técnica Jorge Duarte Pires Valério. Rio de Janeiro: LTC, 2017.

DONEDA, D.; MENDES, L. Data protection in Brazil: New developments and current challenges. In: GURWIRTH, S.; LEENES, R.; HERT, P. de. (Ed.). Reloading data protection: Multidisciplinary Insights and Contemporary Challenges. Londres, Springer, 2014. p. 3-20.

FERRAGUT, SILVA, Maria Rita e Renata Elaine. Direito Tributário Eletrônico. São Paulo: Saraiva 2010.

FIGUEIREDO, Diana. Tecnologia muda às exigências na área de Direito. Disponível em: $<$ https://extra.globo.com/noticias/educacao/profissoes-de-sucesso/tecnologia-muda-asexigencias-da-area-de-Direito-18162491.html>. Acesso em: 10.abr. 2020.

FLORIDI, Luciano. Information ethics, its nature and scope. SIGCAS Comput. Soc., New York, v. 36, n. 3, p. 21-36, 2016. Doi:10.1145/1195716.1195719. Acesso em: 10.abr. 2020.

FLORIDI, Luciano; TADDEO, Mariarosaria. Introduction: What is data ethics? Phil. Trans. R. Soc., Londres, v. 374, n. 2083, 2016. DOI: 10.1098/rsta.2016.0360. Acesso em: 10.abr. 2020.

GANASCIA, Jean-Gabriel. Inteligência artificial. Tradução de Reginaldo Carmello Corrêa de Moraes. São Paulo: Ática, 1997.

HOGEMANN, Edna Raquel. O futuro do Direito e do ensino jurídico diante das novas tecnologias. Disponível em: <http://revistas.faa.edu.br/index.php/FDV/article/view/487/364>. Acesso em: 10.abr. 2020.

IBM. International business machines. New York, 2017a. Disponível em: <https://www. ibm.com/br-pt/>. Acesso em: 10.abr. 2020.

Ross intelligence. New York, 2017b. Disponível em: <http://www.rossintelligence. $\overline{\mathrm{com}} />$. Acesso em: 10.abr. 2020.

Watson. New York, 2017c. Disponível em: <https://www.ibm.com/watson/br-pt/>. Acesso em: 10.abr. 2020. 
JACKSON, Joab. IBM detects skin cancer more quickly with visual machine learning. Computerworld, 2014. Disponível em:

$<$ https://www.computerworld.com/article/2860758/ibm-detects-skin-cancer-more-quicklywith-visual-machine-learning.html>. Acesso em: 10.abr. 2020.

LYON, David. Surveillance as social sorting: privacy, risk, and digital discrimination. Routledge: New York, 2003.

MAYER-SCHONBERGER, V.; CUKIER, K. Big Data: A revolution that will transform how we live, work, and think. New York: First Mariner Books, 2014.

MENDES, Laura Schertel. Privacidade, proteção de dados e defesa do consumidor: linhas gerais de um novo Direito fundamental. São Paulo: Saraiva, 2014.

METZ, Cade. Using AI to detect cancer, not just cats. Wired, 2017. Disponível em:

$<$ https://www.wired. com/2017/05/using-ai-detect-cancer-not-just-cats/>. Acesso em: 10.abr. 2020 .

NICOLA, Daniela Ribeiro Mendes. Estrutura e função do Direito na teoria da sociedade de Luhmann. In: ROCHA, Leonel Severo (Org.). Paradoxos da auto-observação: percursos da teoria jurídica contemporânea. 2. ed. rev. e atual. Ijuí: Ed. Unijuí, 2013. p. 65-67.

OLIVON, Beatriz. Receita testa inteligência artificial em julgamentos Disponível em: <https://www.valor.com.br/legislacao/5473055/receita-testa-inteligencia-artificial-em julgamentos>. Acesso em: 10.abr. 2020.

PAULO, Vicente; ALEXANDRINO, Marcelo. Direito Constitucional Descomplicado. $4^{\mathrm{a}}$ ed. São Paulo: Ed. Método, 2009.

RAVAGNANI, Giovani. Chegou a hora de repensar o judiciário: a força da tecnologia no Direito. Disponível em:< https://www.migalhas.com.br/dePeso/16,MI264827,31047

Chegou+a+hora+de+repensar+o+judiciario+a+forca+da+tecnologia+no>. Acesso em: 10.abr. 2020.

REALE, Miguel. Filosofia do Direito. 19. ed. São Paulo: Saraiva, 1999.

REZENDE, Solange Oliveira (Org.). Sistemas inteligentes: fundamentos e aplicações. Barueri, SP: Manole, 2003.

RODRIGUES, Leo Peixoto; NEVES, Fabrício Monteiro. Niklas Luhmann: a sociedade como sistema. Porto Alegre: Edipucrs, 2012.

ROCHA, Leonel Severo (Org.). Paradoxos da auto-observação: percursos da teoria jurídica contemporânea. 2. ed. rev. e atual. Ijuí: Ed. Unijuí, 2013a.

Epistemologia do Direito: revisitando as três matrizes jurídicas. Revista de Estudos Constitucionais, Hermenêutica e Teoria do Direito (RECHTD), São Leopoldo, v. 5, n. 2, p. 141-149, jul./dez. 2013b. Disponível em: 
<http://revistas.unisinos.br/index.php/RECHTD/article/ view/rechtd.2013.52.06/3934>p. 141.149. Acesso em: 10.abr. 2020.

ROSA, João Luiz Santos. Fundamentos da Inteligência Artificial. Rio de Janeiro: Gen LTC editora nacional, Ed., 2011.

RUSELL, Stuart J.; NORVIG, Peter. Inteligência artificial. Tradução Regina Célia Simille. Rio de Janeiro: Elsevier, 2013.

SILVA, Marisa. Robô advogado usa inteligência artificial para acelerar processos judiciais. Disponível em: <https://olhardigital.com.br/video/robo-advogado-usa-inteligenciaartificial-para-acelerar-processos-judiciais/70215>. Acesso em: 10.abr. 2020.

SILVA, Dejamir. Aplicação da Tecnologia Eletrônica na Prestação Jurisdicional: A Celebridade e a Segurança Jurídica na Busca da efetividade Processual. Disponível em: <https://www.unimep.br/phpg/bibdig/pdfs/2006/GHWKWEXFWLSJ.pdf>. Acesso em: 10.abr. 2020.

SILVA, Rafael Rodrigues da. Estônia está desenvolvendo o primeiro "juiz robô" do mundo. 2019. Disponível em: <https://canaltech.com.br/inteligencia-artificial/estonia-estadesenvolvendo-o-primeiro-juiz-robo-do-mundo-136099/>. Acesso em: 10. abr. 2020

SOARES, Matias Gonsales. A Quarta Revolução Industrial e seus possíveis efeitos no Direito, economia e política. Boletim Jurídico, Uberaba/MG, a. 13, nos 1524. Disponível em: <https://www.boletimjuridico.com.br/doutrina/artigo/4566/a-quarta-revolucao-industrialseus-possiveis-efeitos-Direito-economia-politica>. Acesso em: 10.abr. 2020.

SUTTO, Giovanna. Todos seremos substituídos por robôs? Os mitos e verdades sobre o futuro do trabalho. Disponível em: < https://www.infomoney.com.br/carreira/emprego/noticia/7069854/todos-seremossubstituidos-por-robos-mitos-verdades-sobre-futuro-trabalho>. Acesso em: 10.abr. 2020.

SCHWAB, Klaus. The fourth industrial revolution. Geneva: World Economic Forum, 2016.

SUSSKIND, Daniel. O futuro das profissões (Entrevista). [S.1.], 2017a. (22 min $58 \mathrm{~s}$ ). Disponível em: <https://www.youtube.com/watch?v=Ngf8Jq2nuGc>. Acesso em: 10.abr. 2020.

SUSSKIND, Richard. Tomorrows lawyers: an introducion toyour future. 2 nd ed. Oxford: Oxford University, $2017 b$.

VESTING, Thomas. O Direito moderno e a crise do conhecimento comum. In: FORTES, Pedro; CAMPOS, Ricardo; BARBOSA. Samuel (Coord.). Teorias contemporâneas do Direito: o Direito e as incertezas normativas. 1. ed. Curitiba: Juruá, 2016.

VIDIGAL, Paulo, LIMA, Cáio Cezar Carvalho. O uso de bots e a responsabilidade profissional do advogado. Disponível em < https://www.jota.info/opiniao-e- 
analise/colunas/Direito-digital/o-uso-de-bots-e-a-responsabilidade-profissional-do-advogado13102018. Acesso em: 10.abr. 2020.

ZARSKY, T. Transparent predictions. University of Illinois Law Review, Champaign, v. 2013, n. 4, p. 1503-1570, 2013.

Zavaglia Coelho, Alexandre. A ética e o uso de computação cognitiva (robôs) na área do direito. Revista Direito e Novas Tecnologias - RDTec, Editora Revista dos Tribunais - RT, edição de dezembro de 2018. 